\title{
EUPATORIUM GUIENGOLENSE (ASTERACEAE: EUPATORIEAE), UNA NUEVA ESPECIE DE OAXACA, MEXICO
}

\author{
Leticia Torres-Colin y Jose Luis Villaseñor \\ Instituto de Biología, U.N.A.M. \\ Departamento de Botánica \\ Herbario Nacional \\ Apartado Postal 70-367 \\ 04510 México, D. F.
}

\section{RESUMEN}

Colectas intensivas en el Distrito de Tehuantepec, Oaxaca, llevadas a cabo por el Herbario Nacional, dieron como resultado el descubrimiento de una especie nueva de Eupatorium. Esta especie nueva es descrita e ilustrada; se discuten sus afinidades con E. ovaliflorum y se proporciona una clave para su diferenciación.

\section{ABSTRACT}

Collecting efforts in the District of Tehuantepec, Oaxaca, carried out by the National Herbarium, have resulted in the discovery of a new species of Eupatorium. The new species is described and illustrated, and its affinities with E. ovaliflorum are discussed. A key to determine the two species is provided.

Como resultado del programa intensivo de colecta que el Herbario Nacional del Instituto de Biología, U.N.A.M. lleva a cabo en el Istmo de Tehuantepec, tendiente a la obtención de la flora del Distrito de Tehuantepec, Oaxaca, varias especies nuevas han sido descubiertas. Una de ellas, miembro de la tribu Eupatorieae (Asteraceae), se describe a continuación.

Eupatorium guiengolense L. Torres et Villaseñor, sp. nov. (Fig. 1)

Eupatorio ovalifloro Hook. \& Arn. affine, sed foliis conspicue serratis, tenuioribus, abaxialiter minus pubescentibus et reticulato-venosis, pedunculis longioribus, involucro angustiore et floribus per capitulum paucioribus differt.

Arbustos 1-2 m de alto, profusamente ramificados. Tallos acostillados; ramas jóvenes parduscas, pubescentes, con tricomas multicelulares, los más cortos algo aplicados; ramas maduras pardas oscuras, glabrescentes, con lenticelas a todo lo largo de su superficie. Hojas opuestas, lanceoladas a ovado-lanceoladas, membranáceas, 


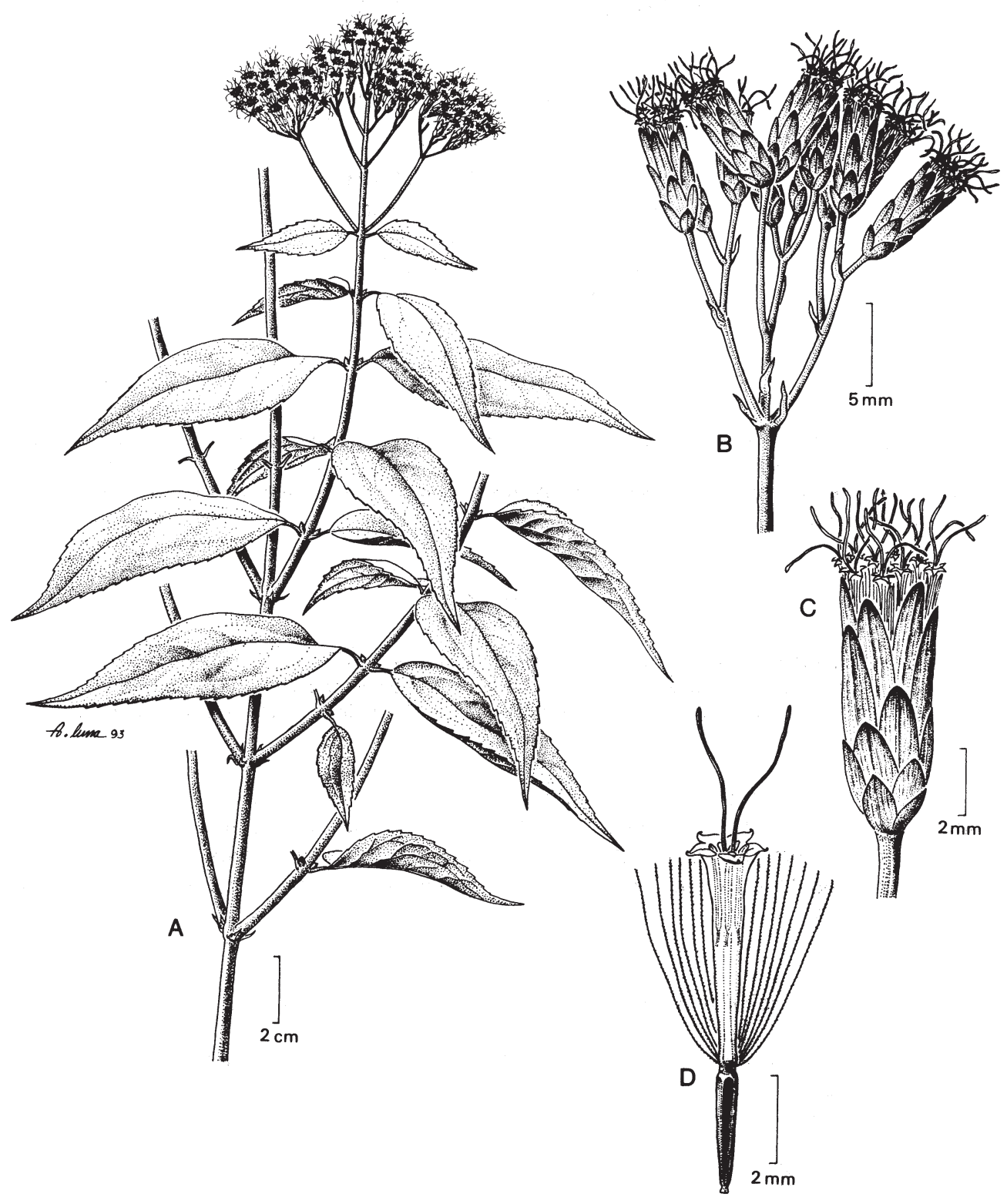

Fig. 1 Eupatorium guiengolense. A. Porción del tallo mostrando la ramificación y una rama terminando en inflorescencia; B. Detalle de la inflorescencia; C. Cabezuela; D. Flor, aquenio y vilano. 
trinervadas, las nervaduras principales originándose $0.3-1.7 \mathrm{~cm}$ por arriba de la base de la lámina, pubescentes a lo largo de las nervaduras, tanto en el haz como en el envés; lámina 2.0-15.6 cm de largo, 0.8-5.6 cm de ancho, ápice acuminado, base atenuada o algo redondeada, márgenes serrados, excepto en la base y en el ápice, el ápice de los dientes con un ligero callo; pecíolos $0.5-3.7 \mathrm{~cm}$ de largo, pubescentes. Cabezuelas numerosas, terminales en las ramas, $16-175$ en cada rama, dispuestas en inflorescencias monotélicas (determinadas) tirsoides, los paracladios constituidos por cimas dicasiales; pedicelos $0.2-1.0 \mathrm{~cm}$ de largo, esparcidamente pilosos, los pedicelos y las ramas de las inflorescencias con pequeñas bracteolas en los sitios de bifurcación. Involucro 7-9 mm de largo, 1-2 mm de ancho, oblongo o angostamente oblongo, graduado; brácteas involucrales escariosas, dispuestas en 5-6 series, la serie externa más corta, el ápice agudo o ligeramente obtuso y con frecuencia mucronulado, los márgenes ciliolados, trinervadas, la vena media más conspicua y terminando en el pequeño mucrón, ligeramente resinosas. Receptáculo plano o ligeramente convexo, desnudo. Flores 9-11, blanquecinas, adquiriendo un tono pajizo en ejemplares de herbario; corolas tubulares, 3.7-4.6 mm de largo, glabras, el tubo y la garganta indiferenciados, los lóbulos triangulares, 0.3-0.5 mm de largo. Anteras alrededor de $1.5 \mathrm{~mm}$ de largo, obtusas en la base, con apéndices oblongo-ovados. Ramas del estilo conspicuamente exertas de la corola, filiformes, ligeramente clavadas. Aquenios 4-5, acostillados, obpiramidales, 2.5-3.3 $\mathrm{mm}$ de largo, pardos oscuros, lustrosos, longitudinalmente estriados en las caras, estrigosos, principalmente a lo largo de las costillas, carpóforo conspicuo. Vilano de 16-26 cerdas capilares, 3.4-4.2 mm de largo, barbeladas, de color pajizo.

TIPO: MEXICO: Oaxaca. Distrito de Tehuantepec, Municipio de Santo Domingo Tehuantepec. Cerro Guiengola, $11 \mathrm{~km}$ al NO de Tehuantepec, carr. a Oaxaca, $16^{\circ}$ 25' $^{\prime}$ $\mathrm{N}, 95^{0} 22^{\prime} \mathrm{W}$, alt. 600-1100 m, selva baja caducifolia, 9 Dic. 1991, A. Campos V. 4234 (holotipo MEXU; isotipos: IEB, TEX, XAL).

Paratipos: MEXICO: Oaxaca. Distrito de Tehuantepec, Municipio de Santo Domingo

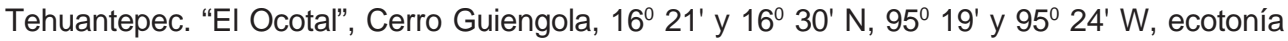
de selva baja caducifolia y bosque de Pinus michoacana, alt. 1100 m, 26 Nov. 1986, M. L. Torres C. 564, A. García M., L. Cortés A., C. Martínez y J. Pérez (ENCB, MEXU, TEX); subida al Cerro Guiengola por la ladera S, por la fábrica de cal, $16^{\circ} 21^{\prime}$ y $16^{\circ} 30^{\prime} \mathrm{N}, 9^{\circ}$ $19^{\prime}$ y $95^{\circ} 24^{\prime}$ W, selva baja caducifolia, 5 Nov. 1986, M. L. Torres C. 679, R. Torres C. y C. Martínez (CHAPA, MEXU, RSA).

Eupatorium guiengolense es un taxón íntimamente relacionado con E. ovaliflorum Hook. \& Arn. [=Chromolaena ovaliflora (Hook. \& Arn.) King \& H. Rob.]. Estas dos especies comparten, entre otras características, un involucro cilíndrico, el cual es varias veces más largo que ancho, graduado, con 4 o más series de brácteas involucrales, una condición arbustiva, un receptáculo de morfología similar y un mismo color de vilano. Sin embargo, E. guiengolense se diferencia por sus hojas serradas, con los dientes conspicuos, los pecíolos más largos, las láminas más delgadas, membranáceas, con el envés menos pubescente, la venación reticulada menos conspicua y prácticamente sin glóbulos de exudado resinoso, el involucro más angosto y generalmente con un número menor de flores por cabezuela (ver la descripción y discusión que sobre E. ovaliflorum hace McVaugh, 
1984).

Por las características de la cabezuela, E. guiengolense se asemeja también a $E$. pulchellum Kunth [=C. pulchella (Kunth) King \& H. Rob.]. Sin embargo, esta última especie puede ser fácilmente diferenciada por su hábito herbáceo, sus hojas alternas y sus brácteas involucrales y flores purpúreas.

Eupatorium guiengolense y E. ovaliflorum son especies características de la vertiente pacífica del territorio nacional. Sin embargo, E. guiengolense es hasta la fecha solamente conocida del Cerro Guiengola, una elevación aislada al NO de la ciudad de Tehuantepec (Torres, 1989). Debido a su posición dentro de la zona semiárida del Istmo de Tehuantepec, el cerro ha resultado ser botánicamente muy interesante, con un alto número de especies endémicas ya descritas (e.g., Agave guiengola H. Gentry, Holographis leticiana T. F. Daniel, Mascagnia leticiana W. R. Anderson, Mimosa torresiae R. Grether y Tetrachyron oaxacana B. L. Turner), E. guiengolense aquí descrita por primera vez, y cuatro especies más en proceso de descripción.

Eupatorium guiengolense es un arbusto más bien escaso, que forma parte de la vegetación característica de la región, la selva baja caducifolia. Sin embargo, solamente se encuentra por arriba de los 600 metros sobre el nivel del mar, hasta la ecotonía que la selva hace con unos manchones de Pinus michoacana Martínez encontrados en la porción más alta del cerro $(1100 \mathrm{~m})$. Sólo se conoce en floración para los meses de noviembre y diciembre.

Eupatorium guiengolense y E. ovaliflorum pueden ser diferenciadas como se indica a continuación:

1. Hojas delgadas, membranáceas, muy esparcidamente pubescentes en el envés y prácticamente sin glóbulos de exudado resinoso; nervadura no conspicuamente reticulada en el envés; hojas mayores con pecíolos 10-37 mm de largo; involucro 1-2 mm de ancho; cabezuelas sobre pedúnculos por lo general mayores de $5 \mathrm{~mm}$ de largo; flores 9-11 por cabezuela.

E. guiengolense

1. Hojas gruesas, coriáceas, conspicuamente pubescentes en el envés y con numerosos glóbulos de exudado resinoso; nervadura conspicuamente reticulada en el envés; hojas mayores con pecíolos 3-10(-13) $\mathrm{mm}$ de largo; involucro por lo general de más de $2 \mathrm{~mm}$ de ancho; cabezuelas sésiles o por lo general sobre pedúnculos de 5 $\mathrm{mm}$ o menos; flores generalmente más de 11 por cabezuela E. ovaliflorum

\section{AGRADECIMIENTOS}

Agradecemos a los Dres. Fernando Chiang, José L. Panero, Billie L. Turner y un revisor anónimo las críticas y observaciones hechas al manuscrito. El Biól. Albino Luna hizo la ilustración que acompaña este trabajo. El trabajo de campo en el Distrito de Tehuantepec fue parcialmente financiado por The National Geographic Society. 
Torres-Colín y Villaseñor: Eupatorium guiengolense, Una Nueva Especie de Oaxaca

\section{LITERATURA CITADA}

McVaugh, R. 1984. Flora Novo-Galiciana. Vol. 12. Compositae. Univ. of Michigan Press. Ann Arbor, Michigan. $1157 \mathrm{pp}$.

Torres C., M. L. 1989. Estudio florístico y descripción de la vegetación del Cerro Guiengola, en el Istmo de Tehuantepec, Oaxaca. Tesis Profesional. Escuela Nacional de Estudios Profesionales, Iztacala. Universidad Nacional Autónoma de México. México, D. F. 81 pp. 